\title{
Correction: In Vitro Activity of Rifampicin and Verapamil Combination in Multidrug- Resistant Mycobacterium tuberculosis
}

Fernanda de Oliveira Demitto, Renata Claro Ribeiro do Amaral, Flaviane Granero Maltempe, Vera Lúcia Dias Siqueira, Regiane Bertin de Lima Scodro, Mariana Aparecida Lopes, Katiany R. Caleffi-Ferracioli, Pedro Henrique Canezin, Rosilene Fressatti Cardoso

The graph legends for Figs 1 and 2 are incorrect. The symbols for RIF and VP are switched. Please see the complete, correct Figs 1 and 2 here.

f open ACcess

Citation: Demitto FdO, do Amaral RCR, Maltempe FG, Siqueira VLD, Scodro RBdL, Lopes MA, et al. (2015) Correction: In Vitro Activity of Rifampicin and Verapamil Combination in Multidrug-Resistant Mycobacterium tuberculosis. PLoS ONE 10(7): e0133343. doi:10.1371/journal.pone. 0133343

Published: July 24, 2015

Copyright: @ 2015 Demitto et al. This is an open access article distributed under the terms of the Creative Commons Attribution License, which permits unrestricted use, distribution, and reproduction in any medium, provided the original author and source are credited. 

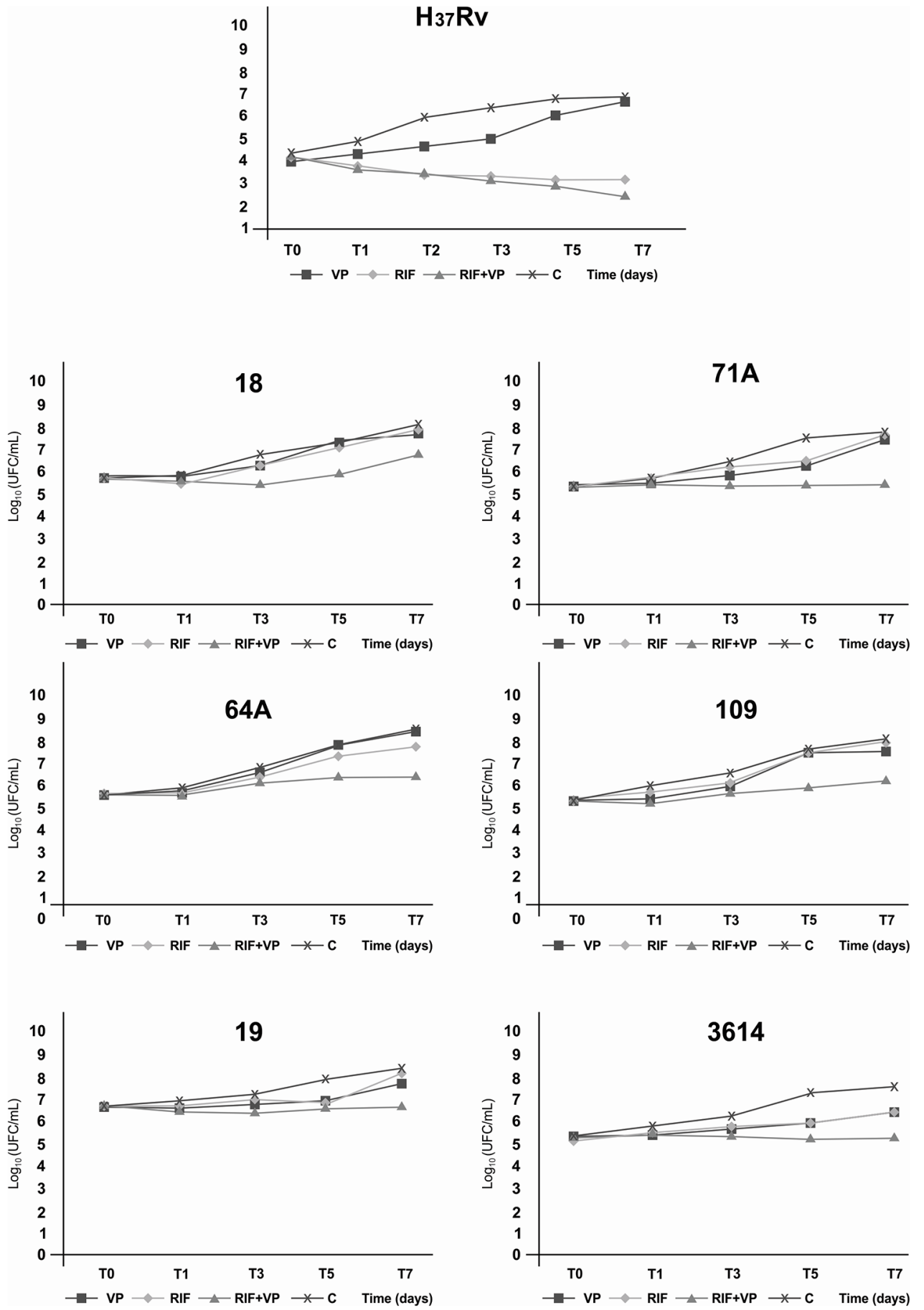

Fig 1. Time-kill curve of the Mycobacterium tuberculosis $\mathrm{H}_{37} \mathrm{Rv}$ reference strain and multidrugresistant clinical isolates $71 \mathrm{~A}, 18,19,109,3614$, and $64 \mathrm{~A}$ exposed to rifampicin (RIF), verapamil (VP), and RIF+VP combination for 7 days at $35-37^{\circ} \mathrm{C}$.

doi:10.1371/journal.pone.0133343.g001 

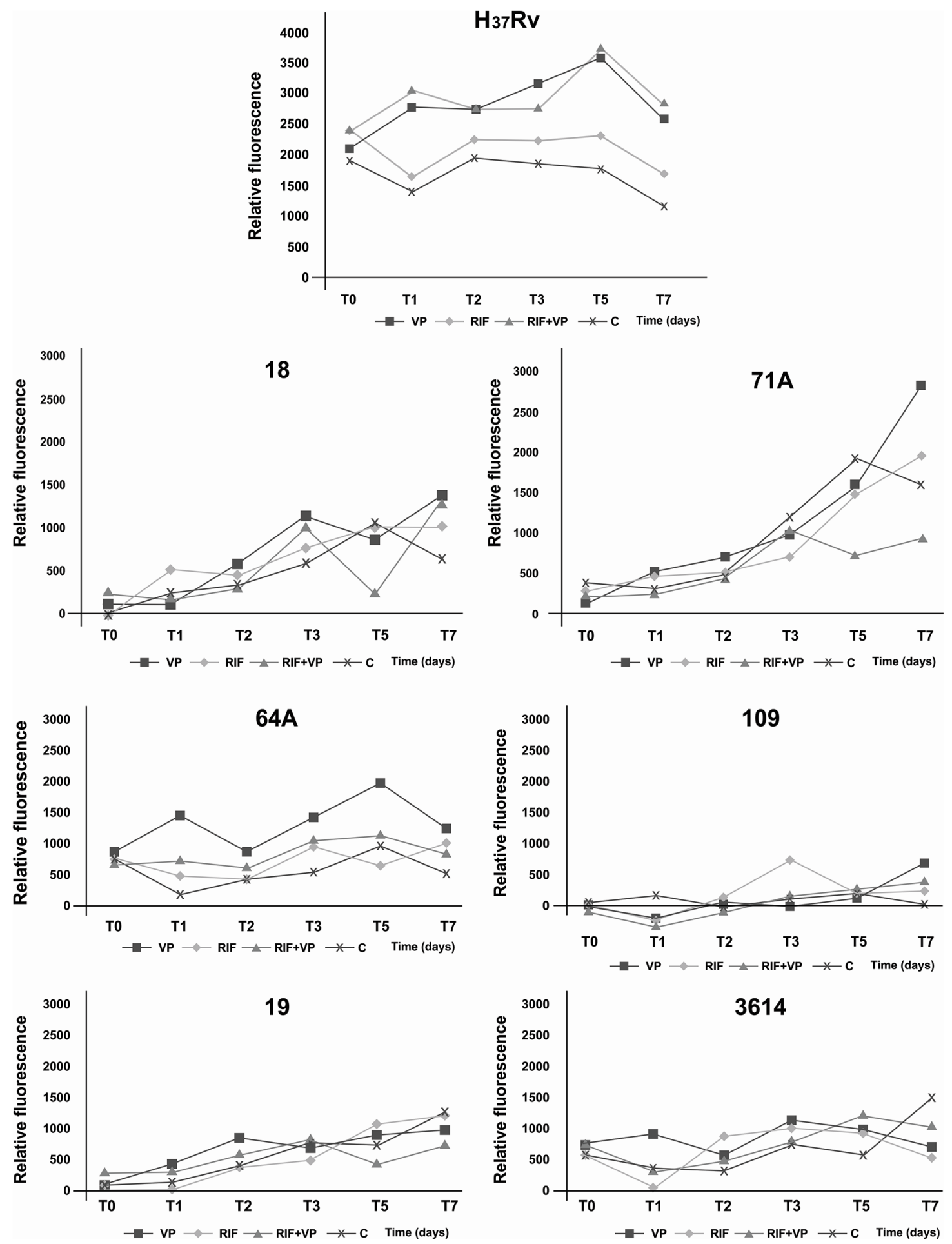

Fig 2. Fluorometry assay. Accumulation of $\mathrm{EtBr}$ in the Mycobacterium tuberculosis $\mathrm{H}_{37} \mathrm{Rv}$ reference strain and multidrug-resistant clinical isolates $71 \mathrm{~A}$, 18 , $19,109,3614$, and $64 \mathrm{~A}$. The mycobacteria were loaded with $0.25 \mu \mathrm{g} / \mathrm{ml} \mathrm{EtBr}$ in the presence of $0.5 \times \mathrm{MIC}$ of verapamil (VP), rifampicin (RIF), and RIF+VP combination for 7 days at $35-37^{\circ} \mathrm{C}$.

doi:10.1371/journal.pone.0133343.g002 


\section{Reference}

1. Demitto FdO, do Amaral RCR, Maltempe FG, Siqueira VLD, Scodro RBdL, Lopes MA, et al. (2015) In Vitro Activity of Rifampicin and Verapamil Combination in Multidrug-Resistant Mycobacterium tuberculosis. PLoS ONE 10(2): e0116545. doi:10.1371/journal.pone.0116545 PMID: 25689777 